\title{
Expresión génica en células de granulosa bovinas de folículos en crecimiento
}

\author{
Jesus Berdugo-Gutiérrez ${ }^{1 *} \bowtie\left(\mathbb{D} ;\right.$; Ariel Tarazona-Morales ${ }^{2} \bowtie\left(\mathbb{0} ;\right.$ Carlos Muskus-López $^{3}{ }^{凶}$;
}

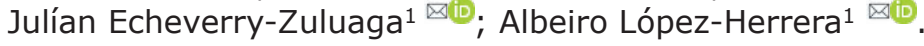

\begin{abstract}
${ }^{1}$ Universidad Nacional de Colombia, Facultad de Ciencias Agrarias. BIOGEM. BIOGENESIS. Medellín, Colombia. 2Universidad Nacional de Colombia. Facultad de Ciencias Agrarias. Medellín, Colombia.

${ }^{3}$ Universidad de Antioquia. Unidad Biología Molecular y computacional PECET. Medellín, Colombia.

*Correspondencia: jaberdugog@unal.edu.co
\end{abstract}

Recibido: Octubre 2020; Aceptado: Junio 2021; Publicado: Noviembre 2021.

\section{RESUMEN}

Objetivo. Comparar la expresión génica en células de granulosa de folículos en crecimiento en dos diferentes especies de bovinos (búfalos y vacas). Materiales y métodos. El RNA obtenido de las células de granulosa de 10 vacas y búfalas vacías fue secuenciado con Novaseq y se analizó la expresión génica diferencial usando EdgeR en Bioconductor y su función de acuerdo con los términos de ontología génica Resultados. El análisis de expresión diferencial mostró grandes diferencias entre las especies, fundamentalmente, la poca participación de los genes asociados a los fenómenos reproductivos del desarrollo folicular, poniendo de manifiesto la importancia del control paracrino del ovario. Se encontró que, entre búfalos y vacunos, no hay correspondencia en la expresión génica de los estados fisiológicos evaluados y aunque se pudieron identificar 6137 genes que tienen expresión diferencial entre las dos especies, no se encontró significancia en genes asociados directamente sobre el desarrollo folicular. Conclusiones. Cada especie tiene su forma de realizar el mismo proceso, aunque son evidentes las diferencias en la expresión de genes asociados a la fosforilación oxidativa. Se requieren nuevas formas de analizar los resultados para poder entender el significado biológico de los hallazgos.

Palabras clave: Búfalos; célula de granulosa; folículo ovárico; transcriptoma; RNA-Seq (Fuente: MeSH).

\section{ABSTRACT}

Objetive. This work compares granulosa cell gene expression using RNA analysis from preovulatory follicles from two different bovine species (buffaloes and cattle) Materials and methods. The RNA was obtained from granulosa cells from ovaries of 10 buffaloes and cattle obtained at the local slaughterhouse, was sequenced with Novaseq and the differential expression was analyzed using EdgeR in Bioconductor, and the function was assigned according to gene ontology terms. Results. Differential gene expressionanalyzes shown great differences between species, but the most important is the low participation of genes associated with reproductive process of follicular development, highlighting the importance of paracrine control of the ovary. It was found that between buffaloes and cattle, there is practically no correspondence in the gene expression of the physiological states evaluated, 6137 genes show differential expression between the two species. Conclusions: Each species has its way of performing the same process, the differences in the expression of the genes associated with oxidative phosphorylation are evident, and new ways to look the results here presented are required, in order to understand the biological significance of the findings.

Keywords: Buffaloes; granulosa cell; ovarian follicle; transcriptome; RNA-Seq (Fuente: MeSH).

Como citar (Vancouver).

Berdugo-Gutiérrez J, Tarazona-Morales A, Muskus-López C, Echeverry-Zuluaga J, López-Herrera A. Expresión génica en células de granulosa bovinas de folículos en crecimiento. Rev MVZ Córdoba. 2022; 27(1):e2013. https://doi.org/10.21897/rmvz.2013 


\section{INTRODUCCION}

Para producir proteína de origen animal se utilizan mamíferos rumiantes con gran cercanía filogenética con los que se han desarrollado sistemas productivos, gracias a esto se ha pensado de forma casi obvia, que muchos de los aspectos de sus respuestas fisiológicas sean extrapolables entre sí, pero la evidencia muestra que no es tan cierto.

Los búfalos (Bubalus bubalis, $2 \mathrm{n}=50$ ) y los vacunos (Bos indicus, $2 \mathrm{n}=60$ ) son bovinos, a los que solo los diferencia su ADN mitocondrial; basados en estudios de las diferencias en la amplificación de fragmentos polimórficos (AFLP) se han descrito tres tribus: búfalos (africano y de agua), vacunos (taurinos y cebuínos) y los bisontes (americanos y europeos) (1).

Búfalos y vacunos poseen un patrón reproductivo similar: monoovular, poliéstrico, estacional con dos o tres ondas foliculares por ciclo. Sin embargo, se ha informado que los búfalos tienen ovarios de menor tamaño, diferente diámetro folicular al momento de la desviación y de la ovulación (2), menor calificación de calidad de oocitos y menos tazas de producción de embriones in vitro. Al comparar la taza de natalidad, expresión de síntomas de celo y respuesta a las biotecnologías reproductivas, las dos especies tienen diferencias importantes, en iguales condiciones medioambientales y de manejo, presentan diferencias importantes, expresión de los síntomas de celo, respuesta a las biotecnologías reproductivas (3), paradójicamente mejor en los búfalos en reproducción natural y mejor en los vacunos en reproducción artificial.

La ovulación es un mecanismo adaptativo desarrollado por la naturaleza para asegurar que un oocito competente, capaz de formar un individuo, sea entregado dentro de un tracto genital endocrinológicamente apto para favorecer la implantación de un embrión y poder llegar a término. Hasta la fecha, los protocolos para la manipulación de la ovulación se basan en la inducción de una onda de crecimiento folicular en un momento del ciclo estral, se debe mencionar que este desarrollo y a la adquisición de la competencia del oocito íntimamente ligados (4). Para producir un oocito competente la comunicación entre las células de granulosa y el oocito es fundamental, en consecuencia, se esperaría que los genes responsables de estas acciones tuvieran un papel determinante en los parámetros reproductivos. La foliculogénesis requiere la acción concertada de numerosos factores intrínsecos y extrínsecos, que determinan la capacidad funcional de la granulosa y el oocito (5), que permiten que se pueda construir una idea sobre el funcionamiento folicular a través del conocimiento generado sobre la expresión de genes. Dada la gran cantidad de información sobre estas interacciones, Khan et al (6) generaron una interfase interactiva llamada GranulosaIMAGE, que informa sobre los perfiles de expresión en las células de granulosa de vacunos en diferentes estados de la foliculogénesis (http://emb bioinfo.fsaa.ulaval. ca/granulosaIMAGE/).

En los mamíferos, el reclutamiento del folículo se da por un escape a la supresión del crecimiento ejercida por la hormona antimulleriana (AMH) y mediante la adquisición de receptores para la hormona folículo estimulante (FSHr), El crecimiento del folículo es dependiente de la FSH hasta el momento de la selección del folículo dominante, que sucede en los vacunos cuando alcanzan $8.5 \mathrm{~mm}$ y en los búfalos a los $7.5 \mathrm{~mm}$. Posteriormente el folículo produce receptores para hormona luteinizante ( $\mathrm{LHr}$ ) (7), lo que genera un descenso en la velocidad de crecimiento que se mantiene hasta el pico preovulatorio de $\mathrm{LH}$.

El uso de herramientas de biología molecular, asociado a los desarrollos en bioinformática permiten avanzar en el conocimiento y entendimiento de los procesos biológicos. Los microarreglos y la secuenciación de nueva generación han permitido avances en el monitoreo de la expresión de los genes; en un solo experimento puede evaluarse la expresión de una gran parte o todo el genoma. Muchas veces la información sobre un fenómeno puede consultarse en las bases de datos públicas, teniendo cuidado en que es heterogénea debido a los aspectos técnicos y las herramientas computacionales usadas para el análisis de esta (8).

Li et al (9), utilizando polimorfismos de nucleótido simple (SNP) estudiaron las bases genéticas del comportamiento reproductivo de 462 búfalos de la raza Mediterranea y encontraron en las células de granulosa de folículos de diferente tamaño, 25 SNPs distribuidos en 13 genes asociados a parámetros reproductivos. De los 13 genes 11 se expresaron en folículos en todos los tamaños, solamente hubo diferencias en la expresión del gen NDUFS2 entre folículos mayores y menores de $8 \mathrm{~mm}$ (9). En otro reporte, los mismos autores 
(9) usaron DNA obtenido de linfocitos de sangre periférica, encontraron SNPs en 40 locus, que se asociaron con 28 genes que pudieron relacionarse con parámetros reproductivos tales como edad al primer, segundo y tercer parto, días abiertos, servicios por concepción, intervalo entre partos, se pudo confirmar que 25 de los 28 genes se expresan en las células de granulosa y que un gen IGFBP7 está presente durante todo el desarrollo folicular (10).

Se ha desarrollado un creciente interés en la búsqueda de explicaciones a estas diferencias, usando evaluaciones comparativas como forma de obtener conocimiento, para desarrollar nuevos conceptos en biología reproductiva y poder ofrecer a los criadores, en este caso, de búfalos alternativas para el mejoramiento de sus hatos. El objetivo del presente trabajo es comparar los resultados de expresión génica en folículos en crecimiento de búfalos y vacunos mediante análisis de RNAseq.

\section{MATERIALES Y MÉTODOS}

Sitio de estudio y obtención de muestras: Este trabajo fue realizado en el laboratorio de Biotecnología de la Universidad Nacional de Colombia-Sede Medellín. Se obtuvieron en la planta de faenado local, ovarios escogidos al azar, de 10 hembras vacunas (Bos indicus) y 10 bufalinas (Bubalus bubalis), no gestantes que fueron llevados al laboratorio en solución salina a $37^{\circ} \mathrm{C}$, antes de dos horas post sacrificio, se aspiraron todos los folículos menores de $7 \mathrm{~mm}$ de cada ovario, el líquido folicular obtenido fue depositado en un plato de Petri y con la ayuda de un estereoscopio fueron identificadas las células de granulosa, que fueron transferidas a viales con 100 ul de PBS y $400 u$ l de RNA later ${ }^{\circledR}$ (Applied Biosystems), congeladas a $-20^{\circ} \mathrm{C}$ hasta la extracción del RNA. Se evalúo el grado de pureza mediante la determinación de la absorbancia A260/280 y A260/230, adicionalmente se calculó el RIN (RNA Integrity Number) mediante el uso del Bioanalizador 2100 Bioanalyzer (Agilent Technologies). Fueron utilizadas muestras con RIN mayor de 5 y una relación A260/280 > 1.8.

Extracción del RNA, síntesis del cDNA y secuenciamiento. El RNA fue extraído usando un kit comercial basado en el uso de membranas de silica y columnas, de acuerdo con las instrucciones del fabricante (RNA easy Mini $\mathrm{Kit}^{\circledR}$, Qiagen), posteriormente para la digestión de restos de DNA se utilizó una DNAasa, libre de RNAasa (Takara, China). Un total de $4 \mu \mathrm{g}$ de RNA purificado fue enviado a Macrogen (Corea), se construyó la librería de cDNA usando TruSeq Stranded mRNA LT Sample Prep Kit (Illumina, San Diego,CA,USA). Se evaluó la calidad de la librería mediante un Agilent Bioanalyzer 2100. Se amplificaron y secuenciaron los fragmentos usando NovaSeq 6000 S4 Reagent Kit, en donde se obtuvieron lecturas con extremos pareados de 100bp.

Ensamblaje y Anotación. Se determinó la calidad de las lecturas usando FastQC Version 0.11.3, el control de calidad se realizó removiendo los adaptadores y solo fueron incluidas las lecturas con un valor de $Q>20$ del $30 \%$ y no más del $5 \%$ de nucleótidos no identificados.

Para mapear los fragmentos de cDNA, se utilizó el software HISAT2 y BOWTIE y GCA_000247795.2 Bovino (11) como genoma de referencia. Las secuencias conocidas fueron identificadas utilizando el modelo StringTie y ensambladas, posteriormente se calculó la cantidad de expresión como FPKM (Fragments Per Kilobase of transcript per Million de lecturas mapeadas) basados en el valor de la cantidad de lecturas y su valor normalizado.

Se excluyeron del análisis de expresión diferencial aquellos genes con 0 lecturas. Los datos fueron transformados y normalizados usando la librería EdgeR en Bioconductor, y para determinar si un gen estaba diferencialmente expresado debía cumplir los siguientes requisitos: tasa de falsos descubrimientos (FDR $\leq 0.05)$ y $\mid \log 2$ Ratio $\mid \geq 1$ (12). Los resultados de los cluster jerárquicos son mostrados en el mapa de expresión con valor de expresión normalizado, utilizando el método euclidiano de ligamiento (12). Se hizo un análisis de enriquecimiento basado en la información registrada en Ontología Génica utilizando la base herramienta g:Profiler (https:bit.cs.ut.ee/ gprofiler/).

\section{RESULTADOS}

La cantidad de RNA obtenido fue un limitante en este trabajo, después del procesamiento para la obtención de librerías, solamente dos muestras una muestra de vacuno y una de búfalo pudieron ser comparadas. En la tabla 1, se puede observar la información relacionada con el material usado para análisis, el $65.87 \%$ y le $93.46 \%$ de las lecturas de búfalos y vacunos, fueron mapeados 
en el genoma de referencia. Para el análisis fueron evaluados 26229 genes, de los cuales solamente 15062 pudieron ser comparados y de estos 6137 cumplieron los parámetros estadísticos de expresión diferencial (fold change $>2 ; \mathrm{p}<0.05$ ), siendo $49.7 \%$ sobreexpresados y $51.3 \%$ subexpresados. Se compararon los genes identificados, búfalos contra vacunos. Se identificaron los 10 genes con mayor expresión diferencial: LRRC8D (Subunidad D, rica en 8 repeticiones de Leucina, KYRU (Kiruneninasa), MTPN (Miotrofina), SERPIN A11 (Variante No 11 de la familia de las Serpinas), SYN2 (Sinapsina II), FAM219A (Miembro A de la familia con secuencia similar 219), SFRP2 (Proteína Frizzeled Secretada 2), NTS (Neurotensina), MSMB (Beta microseminoproteina) LTB4R (Receptor de leucotrienos B4). En contraste, los genes que menos se expresaban eran los genes COX3, COX2, COX1 (Subunidades de la Citocromo B Oxidasa $1,2,3$ ) y ND3, ND4, ND5, ND2 (NADH deshidrogenasa 3,4,5), CYTB (Citocromo oxidasa B), LUZP6 (cremallera de leucina 6) y ACCSL (Carboxilasa sintasa aminoacil propano).

Tabla 1. Parámetros generales de las muestras usadas para análisis.

\begin{tabular}{|c|c|c|}
\hline Parámetro & Búfalo & Vaca \\
\hline Lecturas mapeadas & $\begin{array}{c}31.292 .230 \\
(65.87 \%)\end{array}$ & $\begin{array}{c}59.183 .028 \\
(93.46 \%)\end{array}$ \\
\hline Bases leídas & 4.893.015.296 pb & 6.539.398.924 pb \\
\hline Lecturas & 48.445 .696 & 64.746 .524 \\
\hline$\%$ G/C & 51.83 & 50.30 \\
\hline Q30 & 94.60 & 94.77 \\
\hline $\begin{array}{l}\text { Lecturas después } \\
\text { de remover los } \\
\text { adaptadores }\end{array}$ & $\begin{array}{c}47.508 .526 \\
(Q 30-95.47 \%)\end{array}$ & $\begin{array}{c}63.326 .588 \\
(Q 30-95.70 \%)\end{array}$ \\
\hline Total genes & 33505 & 26229 \\
\hline Genes excluídos & 17333 & 11167 \\
\hline Genes incluídos & 16182 & 15062 \\
\hline $\begin{array}{l}\text { Genes usados para } \\
\text { comparación }\end{array}$ & \multicolumn{2}{|c|}{6137} \\
\hline $\begin{array}{l}\text { Parámetro de } \\
\text { comparación }\end{array}$ & $|\mathrm{fc}|>=2 \& p<0.05$ & $|\mathrm{fc}|>=2 \& p<0.05$ \\
\hline
\end{tabular}

En el análisis de expresión diferencial, se evidencian diferencias entre búfalos y vacunos, encontrando dentro de estos, diferencias relevantes en el clústers en donde están los genes asociados a la respiración. (Figura 1 ).

El análisis los genes diferencialmente expresados arrojo términos en ontología génica relevantes en 5 procesos biológicos: organización de componentes celulares o biogénesis, organización de los componentes celulares, regulación positiva de procesos biológicos, procesos de desarrollo, desarrollo de estructuras anatómicas. Las principales funciones de las moléculas involucradas fueron: Unión, Unión a proteínas, Actividad catalítica, Unión a iones, Unión de iones de metales (Figura 2) y la localización de los eventos: intra celular, célula, parte de una célula, intracelular parte intracelular.

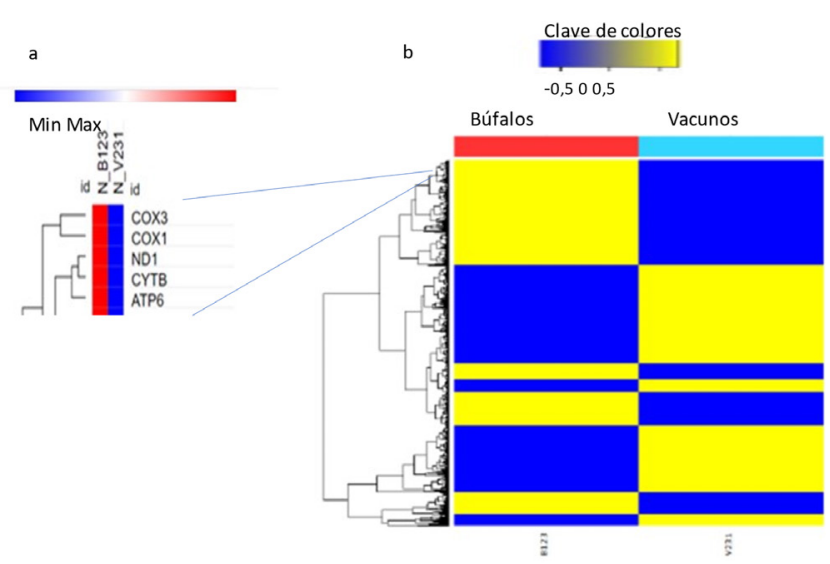

Figura 1. Mapa de expresión diferencial entre búfalos y vacunos, con agrupamiento en clusters. Panel a. Se resalta un ejemplo con genes asociados a la cadena de transporte de electrones y panel $b$; se muestra la comparación de la expresión de los transcriptos entre búfalos y vacas.

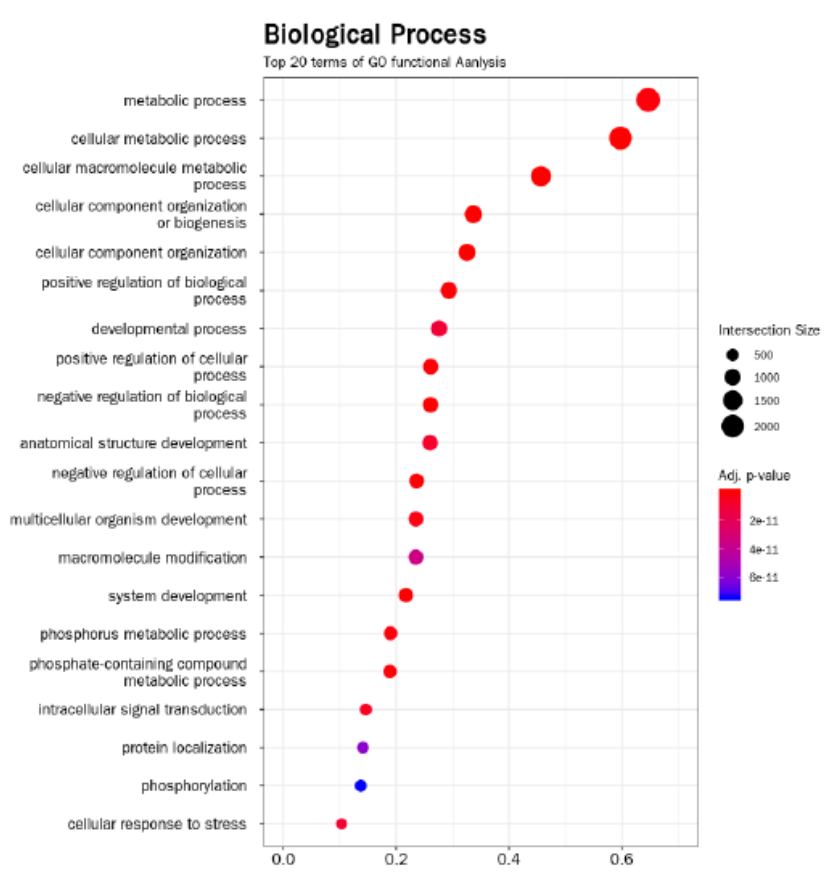

Figura 2. Agrupamiento de genes diferencialmente expresados de acuerdo con, basado en los términos de Ontología Génica. 


\section{DISCUSION}

Este es el primer reporte en la literatura donde se informa sobre la expresión diferencial comparada entre las células de granulosa de búfalos de rio (Bubalus bubalis) y vacunos, ya que la mayoría de los trabajos son en búfalos de pantano (9). Se ha decido enviar este trabajo como reporte de caso debido al escaso número de muestras que cumplieron los requisitos de calidad, para la secuenciación, adicionalmente desde el punto de vista técnico, se ha informado como limitante para este tipo de experimentos: las bajas concentraciones de RNA y la baja calidad del mismo después de la extracción para el secuenciamiento (8).

Se ha enfocado este informe en la comparación de genes en el mismo momento del desarrollo folicular entre las dos especies mencionadas, se observa como los búfalos y los vacunos tienen un patrón diferente de expresión. Buscando con que comparar, se analizaron dos transcriptomas de folículos preovulatorios: uno de vacas GSE39589 (12), y uno búfalos GSE11312 (13), encontrándose nuevamente diferencias en la expresión de genes entre búfalos y vacas en el mismo estadio de desarrollo folicular, similar a los hallazgos de este trabajo.

La comparación de los genes diferencialmente expresados muestra como ninguno de los genes mayormente expresados tienen una función conocida sobre la foliculogénesis o la maduración de los oocitos, es importante mencionar que aquellos genes hay subexpresión, todos están relacionados con la cadena respiratoria, habrá que demostrar que esa diferencia pueda ser una explicación a lo observado por Marin et al, sobre el incremento en la producción de radicales libres en los cultivos de embriones in vitro de búfalo y la necesidad de adicionar antioxidantes para incrementar las tazas de producción de embriones in vitro (14).

Teniendo en cuenta los parámetros mencionados para la expresión diferencial y buscando alguna relación directa con el desarrollo folicular, se identificaron algunos genes que pudieran tener diferencias en su expresión y se encontró que en búfalos los transcriptos AMH, INHA INHBA, PTEN, VEGFD VNN1 tenían expresión disminuida y que IGF2R se encontraba aumentado. Otros genes asociados al desarrollo folicular como AMHR, FSH, p53, CDK1, CYP51A1, CYP19A1, FOXO 1, LHR, TNFA no tuvieron expresión diferencial entre las dos especies.
Li et al (10), evaluaron el genoma del búfalo buscando algunos marcadores y/o genes que pudieran estar asociados con parámetros reproductivos, identificando 13 genes candidatos que se expresaban en folículos pequeños, estos resultados fueron comparados con los obtenidos en este trabajo y se encontró que únicamente NDUFS2 Y ARID4B fueron expresados diferencialmente, mientras que PRDM5, GDF9, COL23A1, SCG5, PELI2, ABCC4, ACCS,TPCN1,TBCB, CDH10, LY86 no tuvieron cambios en la expresión en las dos especies evaluadas. Al igual que en este trabajo los genes asociados directamente con el desarrollo de folículos no tuvieron expresión diferencial.

La evidencia muestra entonces que la búsqueda de explicaciones a las diferencias observadas en los parámetros reproductivos, no se asocia a la expresión de los genes directamente involucrados en el desarrollo del folículo. Algunos autores han propuesto como marcadores del proceso ovulatorio, moléculas asociadas a la inflamación (5). No se debe dejar de tener en cuenta el significado que pueda tener la expresión diferencial de unos pocos genes en el contexto de todo el transcriptoma de la célula.

El análisis de ontología génica muestra como en las dos especies a las células de granulosa le están sucediendo los mismos procesos, tienen muchas moléculas para unión, algo común en las células estudiadas pues los fenómenos del desarrollo folicular son gobernados por las gonadotropinas $\mathrm{FSH}$ y $\mathrm{LH}$ producidas en la hipófisis, así que lo que en últimas hacen las gonadotropinas es activar vías como el de la MAP Kinasa para así facilitar la proliferación de las células la expansión del cúmulus (15). Otros trabajos muestran que en folículos antrales de búfalo están enriquecidas las vías de señalización para el funcionamiento de los ribosomas y la fosforilación oxidativa (16), adicionalmente la activación de las células del cúmulus depende de la acción efectora de las moléculas de la familia TGF $\beta$ producida por el oocito, evaluadas en este experimento pero que no tuvieron expresión diferencial.

Se debe tener en cuenta que más allá de la presencia o ausencia de expresión o de genes específicos que las muestras usadas en este experimento corresponden a folículos que se están preparando para la fase de máximo crecimiento previo a la desviación folicular y que tienen un oocito que ha llegado al máximo de su tamaño (17). 
Encontrar la expresión de genes asociados a la unión, está de acuerdo con la naturaleza fisiológica de los folículos que en ese tamaño son un tejido proliferativo que para su desarrollo necesita una gran cantidad de RNA mensajeros de señales (18) para cumplir su función: inmediata de ovulación e indirectamente un oocito competente para formar un embrión. Otros trabajos donde hay comparación de expresión diferencial en folículos informan que existen en los búfalos 110 genes diferencialmente expresados pertenecientes a 14 vías metabólicas y que para las vacas se encontraron 446 genes que pertenecían a 10 vías metabólicas (14).

Solo algunas publicaciones en reproducción han tratado de hacer comparaciones entre búfalos y vacas con enfoque global del problema, la tendencia de la mayoría de las publicaciones es confirmar resultados puntuales de las diferencias aquí informadas y hacer postulados generales del proceso biológico estudiado. Se puede encontrar con facilidad reportes sobre las diferencias en genes específicos en eventos puntuales como la señalización para el reinicio de la meiosis (5), o el papel de los factores transformantes sobre el desarrollo folicular. De la fisiología de las células de granulosa y su papel en el desarrollo folicular se conoce mucha información en vacas, pero es escasa en búfalos y mucho menos su comparación. A la fecha, solo se encuentra un artículo en el estudio de la transcriptómica de las células de granulosa bufalinas, utilizando RNAseq en material de planta de faenado, encontrando expresión diferencial en 595 genes, cuando se comparan los estados iniciales con los finales del desarrollo folicular (10). La comparación entre funciones muestra como hacen lo mismo con diferentes moléculas, los búfalos involucran más moléculas que las vacas lo que les pudiera dar una ventaja para la ovulación al tener más opciones de rutas celulares disponibles

No debe olvidarse que menos del $1 \%$ de los genes anotados tienen una expresión restringida a un tipo de tejido (19), así pues derivado de los estudios de secuenciación siempre el principal hallazgo habrá de ser la expresión basal de todos los genes, será inevitable tener miles de genes pero es fundamental entender que análisis dependerá fundamentalmente del contexto del experimento o los objetivos del investigador o tendrá que analizarse con sumo cuidado antes de realizar trabajos que generen miles de datos, que pudieran confundir más que ayudar al investigador.
En conclusión, con las limitaciones asociadas al tamaño de la muestra estudiada, los hallazgos obtenidos: en donde no hay el mismo patrón de expresión génica, muestran que, a pesar de ser bovinos, búfalos y vacas, tienen su forma específica de desarrollar los folículos, o pudiera decirse que a pesar de usar las mismas señales por lo menos que no involucran las mismas moléculas. Ese es uno de los resultados importantes de este trabajo. Debido a que los genes conocidos, que se asocian al desarrollo folicular no se expresaron diferencialmente por ahora no se puede cumplir el objetivo de explicar las diferencias en el comportamiento reproductivo entre estas dos especies.

La alta correspondencia del resultado obtenido cuando se analizan las redes o funciones biológicas más frecuentes en el evento estudiado entre las dos especies analizadas, si muestra que las dos especies están teniendo el mismo evento biológico: crecimiento de una estructura dentro del organismo con alta producción metabólica, proliferación celular, producción de señales para todos los eventos que sucederán, cuya consecuencia es la ovulación.

La comparación entre especies, es algo novedoso, especialmente en el área de la biología reproductiva, estudiar el mismo fenómeno en igualdad de condiciones entre búfalos y vacas muestra como cada especie ha desarrollado su propia forma de realizar sus procesos, por lo que estudiar las diferencias con la metodología planteada requiere de una forma diferente de ver el problema y la información obtenida es la base para el análisis de la complejidad de los fenómenos estudiados, con la obligatoriedad de verlos de una manera no reduccionista, a la que estamos acostumbrados, por ahora las expectativas superaron nuestro nivel de entendimiento

\section{Conflicto de intereses}

El manuscrito fue preparado y revisado con la participación de todos los autores, quienes declaramos que no existe ningún conflicto de intereses que ponga en riesgo la validez de los resultados presentados.

\section{Financiación}

Este estudio fue financiado por la Universidad Nacional de Colombia - Sede Medellín y la Asociación Colombiana de Criadores de Búfalos. 


\section{REFERENCIAS}

1. Buntjer JB, Otsen M, Nijman IJ, Kuiper MTR, Lenstra JA. Phylogeny of bovine species based on AFLP fingerprinting. Heredity. 2002; 88(1):46-51. https://doi. org/10.1038/sj.hdy.6800007.

2. Gimenes $L U$, Ferraz $M L$, Fantinato-Neto $P$, Chiaratti MR, Mesquita LG, Sá Filho MF, Meirelles FV, Trinca LA, Rennó FP, Watanabe YF, Baruselli PS. The interval between the emergence of pharmacologically synchronized ovarian follicular waves and ovum pickup does not significantly affect in vitro embryo production in Bos indicus, Bos taurus, and Bubalus bubalis. Theriogenology. 2015; 83(3):385-93. https://doi. org/10.1016/j.theriogenology.2014.09.030

3. Drost M. Bubaline versus bovine reproduction. Theriogenology. 2007; 68(3):447-449. https://doi.org/10.1016/j. theriogenology.2007.04.012

4. Scaramuzzi RJ, Baird DT, Campbell BK, Driancourt MA, Dupont J, Fortune JE, Gilchrist RB, Martin GB, McNatty KP, McNeilly AS, Monget P. Regulation of folliculogenesis and the determination of ovulation rate in ruminants. Reprod. Fert. Dev. 2011; 23(3):444-467. https://doi.org/10.1071/ RD09161.

5. Gougeon A. Human ovarian follicular development: from activation of resting follicles to preovulatory maturation. Annal d'endocrin. 2010; 71(3):132-43. https:// doi.org/10.1016/j.ando.2010.02.021

6. Khan DR, Landry DA, Fournier É, Vigneault C, Blondin P, Sirard M-A. Transcriptome metaanalysis of three follicular compartments and its correlation with ovarian follicle maturity and oocyte developmental competence in cows. Physiol. Genom. 2016; 48(8):633-643. https://doi.org/10.1152/ physiolgenomics.00050.2016

7. Nivet A-L, Bunel A, Labrecque R, Belanger J, Vigneault $\mathrm{C}$, Blondin $\mathrm{P}$, et al. FSH withdrawal improves developmental competence of oocytes in the bovine model. Reproduction. 2012; 143(2):165-171. https://doi. org/10.1530/REP-11-0391
8. Robert C. Microarray analysis of gene expression during early development: A cautionary overview. Reproduction. 2010; 140:787-801. https://doi.org/10.1530/ REP-10-0191

9. Li J, Liu J, Liu S, Plastow G, Zhang C, Wang $Z$, et al. Integrating RNA-seq and GWAS reveals novel genetic mutations for buffalo reproductive traits. Anim Reprod Sci. 2018; 197:290-295 https://doi.org/10.1016/j. anireprosci.2018.08.041

10. Li J, Li Z, Liu S, Zia R, Liang A, Yang L. Transcriptome studies of granulosa cells at different stages of ovarian follicular development in buffalo. Anim Reprod Sci. 2017; 187:181-192. https://doi. org/10.1016/j.anireprosci.2017.11.004

11. Daetwyler HD, Capitan A, Pausch H, Stothard $P$, Van Binsbergen $R$, Brøndum RF, Liao X, Djari A, Rodriguez SC, Grohs C, Esquerre $D$. Whole-genome sequencing of 234 bulls facilitates mapping of monogenic and complex traits in cattle. Nature Genetics. 2014; 46(8):858-865. https:// doi.org/10.1038/ng.3034

12. Hatzirodos $\mathrm{N}$, Hummitzsch $\mathrm{K}$, Irving-Rodgers $\mathrm{HF}$, Harland ML, Morris SE, Rodgers RJ. Transcriptome profiling of granulosa cells from bovine ovarian follicles during atresia. BMC Genom. 2014; 15(1):1-26. https://doi. org/10.1186/1471-2164-15-40

13. Rao JU, Shah KB, Puttaiah J, Rudraiah M. Gene Expression Profiling of Preovulatory Follicle in the Buffalo Cow: Effects of Increased IGF-I Concentration on Periovulatory Events. PLoS ONE. 201; 6(6):e20754 https://doi. org/10.1371/journal.pone.0020754.

14. Marin DF, Souza EB, Brito VC, Nascimento CV, Ramos AS, Rolim ST, Costa NN, Cordeiro MD, Santos SD, Ohashi OM. In vitro embryo production in buffaloes: from the laboratory to the farm. Anim. Reprod. Br. 2019; 16:260266. https://doi.org/10.21451/1984-3143AR2018-0135 
15. Tremblay PG, Sirard M-A. Transcriptomic analysis of gene cascades involved in protein kinase $A$ and $C$ signaling in the $K G N$ line of human ovarian granulosa tumor cells. Biol Reprod. 2017; 96(4):855-865. https://doi. org/10.1093/biolre/iox024

16. Hummitzsch $\mathrm{K}$, Irving-Rodgers $\mathrm{HF}$, Hatzirodos N, Bonner W, Sabatier L, Reinhardt DP, Sado $Y$, Ninomiya Y, Wilhelm D, Rodgers RJ. A new model of development of the mammalian ovary and follicles. Plos One. 2013; 8(2):e55578 https://doi.org/10.1371/ journal.pone.0055578

17. Khan DR, Guillemette C, Sirard MA, Richard FJ. Characterization of FSH signalling networks in bovine cumulus cells: a perspective on oocyte competence acquisition. Mol. Hum. Reprod. 2015; 21(9):688-701. https://doi. org/10.1093/molehr/gav032
18. McGettigan PA, Browne JA, Carrington SD, Crowe MA, Fair T, Forde N, et al. Fertility and genomics: comparison of gene expression in contrasting reproductive tissues of female cattle. Reprod Fert Dev. 2016; 28(2):11. https://doi.org/10.1071/RD15354

19. Takeo S, Kawahara-Miki R, Goto H, Cao F, Kimura K, Monji Y, et al. Ageassociated changes in gene expression and developmental competence of bovine oocytes, and a possible countermeasure against age-associated events. Mol Rep Dev. 2013; 80(7):508-521. https://doi. org/10.1002/mrd.22187 